\title{
A simple constructive proof of Kronecker's Density Theorem
}

\begin{abstract}
Douglas Bridges and Peter Schuster
Douglas Bridges lehrt seit 1999 als Professor für Reine Mathematik an der Universität von Canterbury in Christchurch, Neuseeland. Neben seinem Wirken in der konstruktiven Mathematik hat er unter anderem über mathematische Fragen der Nationalökonomie publiziert. Er ist Mitherausgeber von Zeitschriften wie dem „Mathematical Logic Quarterly“. Zusammen mit Errett Bishop schrieb er den Grundlehrenband „Constructive Analysis“.

Peter Schuster ist Privatdozent an der Universität München, Oberassistent am dortigen Lehrstuhl für Mathematische Logik und arbeitet unter anderem auf dem Gebiet der konstruktiven Mengenlehre, der punktfreien Topologie und der formalen kommutativen Algebra.
\end{abstract}

Leopold Kronecker (1823-1891) achieved fame for his work in a variety of areas of mathematics, and notoriety for his unrelenting advocacy of a constructivist, almost finitist, philosophy of mathematics.

In the present note we give a direct and elementary proof of Kronecker's Density Theorem [2] (see also [3, pp. 49-109]):

Theorem 1. If the real number $\theta$ is distinct from each rational multiple of $\pi$, then the set $\left\{\mathrm{e}^{\mathrm{i} n \theta} \mid n \in \mathbb{Z}\right\}$ is dense in the unit circle.

It is hard to believe that our proof is absolutely original, but it seems sufficiently natural to be worth presenting to the public.

Am Anfang der später von Hermann Weyl, Edmund Hlawka und deren Nachfolgern perfektionierten Theorie der Gleichverteilung stand unter anderem der Kroneckersche Dichtheitssatz: Hat eine komplexe Zahl vom Betrag 1 als Argument ein irrationales Vielfaches der Kreiszahl $\pi$, so bilden die Potenzen dieser komplexen Zahl eine dichte Teilmenge des Einheitskreises. Bekanntlich ist die Menge jener Potenzen endlich, wenn das Argument der Basis ein rationales Vielfaches von $\pi$ ist. In der vorliegenden Arbeit geben die Autoren einen direkten und elementaren Beweis des Kroneckerschen Satzes an, auch um dessen konstruktive Gültigkeit nachzuweisen. 
Moreover, in the spirit of Kronecker's views and work, it is one hundred per cent constructive. $^{1}$

Proof. Since the set $\mathbb{Q} \pi$ of rational multiples of $\pi$ is dense in $\mathbb{R}$, it is enough to prove that for each $t \in \mathbb{R}$ and each positive $\varepsilon$ in $\mathbb{Q} \pi$ there exists $n \in \mathbb{Z}$ such that $\left|\mathrm{e}^{\mathrm{i} t}-\mathrm{e}^{\mathrm{i} n \theta}\right|<\varepsilon$, or, equivalently, that for all such $t, \varepsilon$ there exist integers $p, q$ such that $|p \theta-t+2 q \pi|<\varepsilon$. We may assume that $0<\theta<2 \pi$ : for in the general case, since $\theta$ is distinct from each rational multiple of $\pi$, there exists an integer $k$ such that $0<\theta-2 k \pi<2 \pi$; if we can compute $p, q \in \mathbb{Z}$ such that

$$
|p(\theta-2 k \pi)-t+2 q \pi|<\varepsilon,
$$

then we have

$$
|p \theta-t+2(q-k p) \pi|<\varepsilon .
$$

Next we show that it suffices to prove the case $t=0$. Indeed, supposing that we have found $p, q \in \mathbb{Z}$ such that $|p \theta+2 q \pi|<\varepsilon$, for arbitrary $t \in \mathbb{R}$ we can find an integer $k$ such that

$$
\left|k-\frac{t}{p \theta+2 q \pi}\right|<1 \text {. }
$$

(Note that $p \theta+2 q \pi$ is distinct from 0 , by our hypothesis on $\theta$ ). Then

$$
|k p \theta-t+2 k q \pi|=|p \theta+2 q \pi| \cdot\left|k-\frac{t}{p \theta+2 q \pi}\right|<|p \theta+2 q \pi|<\varepsilon .
$$

For our final simplification we may assume that $0<\varepsilon<\min \left\{\frac{\pi}{2}, \theta\right\}$.

The idea behind the rest of the proof is simple. Starting at the point $\mathrm{e}^{\mathrm{i} \theta}$, we move anticlockwise round the unit circle in steps of arc length $\theta$ until we pass the positive $x$-axis. Since $\theta$ is not a rational multiple of $\pi$, this brings us to a point $\mathrm{e}^{\mathrm{i} \theta_{1}}$ with $0<\theta_{1}<\theta$, where $2 \pi+\theta_{1}$ is an integer multiple of $\theta$; so $\theta_{1}-\theta$ is distinct from $-\varepsilon$. If $\theta_{1}-\theta>-\varepsilon$, then we are finished; if $\theta_{1}-\theta<-\varepsilon$, then we repeat the procedure with $\theta$ replaced by $\theta_{1}$. It is easy to give an upper bound for the number of times this procedure must be iterated to ensure that we arrive at the desired approximation to 0.

Here is the precise argument. Taking $\theta_{0}=\theta$, suppose that for some $k \geqslant 1$ we have found real numbers $\theta_{0}=\theta, \ldots, \theta_{k-1}$, positive and distinct from each rational multiple of $\pi$, and integers $p_{1}, \ldots, p_{k-1}>1$ such that

$$
0<\theta_{i}=p_{i} \theta_{i-1}-2 \pi<\theta_{i-1} \quad(1 \leq i \leq k-1) .
$$

Compute

$$
p_{k}=\min \left\{n \in \mathbb{N} \mid n \theta_{k-1}>2 \pi\right\},
$$

\footnotetext{
${ }^{1}$ Several other proofs of Kronecker's Density Theorem, including Kronecker's original one, are given in Chapter XXIII of [1]. - From today's perspective, Kronecker's theorem stood at the beginning of the theory of uniform distribution continued by Hermann Weyl, and brought to some perfection by the Vienna school around Edmund Hlawka. Kronecker's theorem is a by-product of Weyl's approach to uniform distribution, which can be constructivised relatively easily [4].
} 
and set $\theta_{k}=p_{k} \theta_{k-1}-2 \pi$. Then $p_{k}>1, \theta_{k}>0$, and

$$
\theta_{k}-\theta_{k-1}=\left(p_{k}-1\right) \theta_{k-1}-2 \pi<0 \text {. }
$$

Also, $\theta_{k}$ and $\theta_{k}-\theta_{k-1}$ are distinct from each rational multiple of $\pi$, so either $\theta_{k}-\theta_{k-1}>$ $-\varepsilon$ or else $\theta_{k}-\theta_{k-1}<-\varepsilon$ (recall that $\varepsilon \in \mathbb{Q} \pi$ ). In the first case, a simple induction using (1) shows that there exists an integer $q$ such that

$$
0<\theta_{k}-\theta_{k-1}=\left(p_{k}-1\right) \theta_{k-1}-2 \pi=\left(p_{k}-1\right) p_{k-1} \cdots p_{1} \theta-2 q \pi<\varepsilon,
$$

and we terminate the procedure. In the second case we proceed to the construction of $p_{k+1}$ and $\theta_{k+1}$. To show that this process must eventually stop, choose a positive integer $M$ such that $M \varepsilon>\theta$. If the process did not end with the construction of $\theta_{M}$ and $p_{M}$, then for $1 \leq k \leq M$ we would have $0<\theta_{k}<\theta_{k-1}-\varepsilon$; whence $0<\theta_{M}<\theta-M \varepsilon<0$, a contradiction. Thus the process must stop at or before the $M$ th iteration.

\section{Acknowledgement}

We are grateful to Hajime Ishihara for stimulating discussions, and to the Deutscher Akademischer Austauschdienst for supporting the first author as a Gastprofessor in the Mathematisches Institut der Universität München while the paper was revised into its final form. At a very late stage Hubert Kalf gave a useful hint.

\section{References}

[1] Hardy, G.H.; Wright, E.M.: An Introduction to the Theory of Numbers. 4th ed., Clarendon Press, Oxford 1960

[2] Kronecker, L.: Näherungsweise ganzzahlige Auflösung linearer Gleichungen. Monatsberichte Königl. Preuß. Akad. Wiss. Berlin (1884), 1179-1193 and 1271-1299.

[3] Hensel, K. (ed.): Leopold Kroneckers Werke. Bd. III, Halbbd. I. Teubner, Leipzig 1899, and Chelsea Publ. Co., New York 1968.

[4] Taschner, R.J.: Eine Ungleichung von van der Corput und Kemperman. Monatsh. Math. 91(2) (1981), 139_ 152.

Douglas Bridges

Department of Mathematics \& Statistics

The University of Canterbury

Private Bag 4800

Christchurch, New Zealand

e-mail: douglas.bridges@canterbury.ac.nz

Peter Schuster

Mathematisches Institut

Universität München

Theresienstraße 39

D-80333 München, Germany

e-mail: peter.schuster@mathematik.uni-muenchen.de 